\title{
Mechano-Synthesized Orthoferrite Starting from Wüstite Assisted by SPS
}

\author{
Claudia Alicia Cortés-Escobedo ${ }^{*}$, Félix Sánchez-De Jesus ${ }^{2}$, Ana María Bolarín-Mirón ${ }^{2}$, \\ Sophie Nowak ${ }^{3}$, Elizabeth Piazzini Juárez-Camacho', Sebastián Díaz de la Torre1, \\ Raúl Valenzuela ${ }^{4}$ \\ ${ }^{1}$ Instituto Politécnico Nacional, Centro de Investigación e Innovación Tecnológica, CIITEC, México D.F., México \\ ${ }^{2}$ Universidad Autónoma del Estado de Hidalgo-AACTyM, Mineral de la Reforma, Pachuca, México \\ ${ }^{3}$ ITODYS, UMR, CNRS 7086, Université de Paris-Diderot, Paris, France \\ ${ }^{4}$ Instituto de Investigaciones en Materiales-UNAM, México D.F., México \\ Email: ${ }^{*}$ claudia.alicia.cortes@gmail.com
}

Received 28 January 2014; revised 4 March 2014; accepted 11 March 2014

Copyright (C) 2014 by authors and Scientific Research Publishing Inc.

This work is licensed under the Creative Commons Attribution International License (CC BY). http://creativecommons.org/licenses/by/4.0/

(c) (i) Open Access

\begin{abstract}
Stoichiometric mixtures of $\mathrm{FeO}$ and $\mathrm{Y}_{2} \mathrm{O}_{3}$ were milled and heat treated to obtain yttrium iron garnet, $\mathrm{Y}_{3} \mathrm{Fe}_{5} \mathrm{O}_{12}$. Two types of heating systems were used: one, a spark plasma sintering machine and the second, an electrical oven. The magnetic properties of the resulting specimens have been analyzed and discussed as a function of the grain size and the particles' morphology. The partial formation of garnet and orthoferrite phases was revealed on the obtained powder through microstructural analyses after $9 \mathrm{~h}$ of ball milling. The milled powders were transformed into the orthoferrite phase after the SPS-treatment at $700^{\circ} \mathrm{C}$ and $900^{\circ} \mathrm{C}$. Magnetic-saturation studies revealed magnetic responses up to $12.7 \mathrm{emu} / \mathrm{g}$ for specimens SPS-treated at $700^{\circ} \mathrm{C}$, whereas $2.1 \mathrm{emu} / \mathrm{g}$ for samples SPS-treated at $900^{\circ} \mathrm{C}$. Conventionally treated specimens at $700^{\circ} \mathrm{C}$ developed $0.36 \mathrm{emu} / \mathrm{g} \mathrm{of}$ magnetization, while $0.93 \mathrm{emu} / \mathrm{g}$ was registered for those treated at $900^{\circ} \mathrm{C}$.
\end{abstract}

\section{Keywords}

Wüstite; Orthoferrite; Mechano-Synthesis; SPS; Magnetic Properties

\section{Introduction}

Yttrium iron garnet ( $\mathrm{YIG}, \mathrm{Y}_{3} \mathrm{Fe}_{5} \mathrm{O}_{12}$ ) is a ferromagnetic material that has a wide range of applications in the communication field because it possesses the highest quality factor in the range 1 - $10 \mathrm{GHz}$, the bandwidth of

\footnotetext{
${ }^{*}$ Corresponding author.
} 
microwave [1]-[3]. YIG is often used in devices such as circulators, isolators, oscillators, phase shifters for the microwave region like storage units, sensors, lasers, phosphorescent sources, and electrochemical devices. Its frequent use is due to its electromagnetic properties such as large Faraday rotation, low propagation loss, high and controllable saturation magnetization, moderate thermal expansion coefficients, energy transfer efficiency, and narrow line-width in ferromagnetic resonance [4] [5]. On the other hand, yttrium orthoferrite $\left(\mathrm{YFeO}_{3}\right)$ has been used as a magnetic insulator, for information processing, magneto-optical devices, cathodes and catalysts supports. This is due to its magnetic moment in the Fe sublattice, which is antiparallel, and its transparency in the visible and near infrared regions [6]-[10].

The conventional methods of obtaining YIG consist in a solid-state reaction of $\mathrm{Fe}_{2} \mathrm{O}_{3}$ and $\mathrm{Y}_{2} \mathrm{O}_{3}$ at high sintering temperatures $\left(>1350^{\circ} \mathrm{C}\right)$ and long sintering times $(>10 \mathrm{~h})$ in conventional furnaces [1] [4], leading to an increased particle size. Other techniques to obtain YIG are co-precipitation [5] [11] [12], auto-combustion of nitrate-citrate gel [13]-[15], spray plasma processes [15], and microwave [16] [17]. The conventional method of obtaining orthoferrite is mixing the precursor powders of $\mathrm{Y}_{2} \mathrm{O}_{3}$ and $\mathrm{Fe}_{2} \mathrm{O}_{3}$ in stoichiometric relation and heating to $1100^{\circ} \mathrm{C}[1]$.

It is well known that magnetic properties such as the coercive field and saturation magnetization are strongly dependent upon the microstructure, shape, and size of crystals, crystal size distribution, and phase purity [4] [14].

The mechano-synthesis process is often carried out through an efficient high-energy ball milling technique that reduces processing time and energy consumption due to low operation temperatures. This converts mechanical energy into chemical energy [18]. However, since the spark plasma sintering (SPS) technique can be carried out within just few minutes, it allows for a lower temperature and shorter sintering time [19], while keeping the final products small grain sized.

Another important consideration has to be made regarding the magnetic properties related to non-stoichiometry. Many efforts have been made to produce mostly pure YIG, but only a few studies have been found to correlate nonstoichiometry and oxidation number effects on the final magnetic properties in both YIG and orthoferrite ceramics [20]-[22].

Fernández-García et al obtained bulk YIG specimens by calcining powder from $1000^{\circ} \mathrm{C}$ to $1200^{\circ} \mathrm{C}$ and starting from a mixture of $\mathrm{Fe}_{2} \mathrm{O}_{3}$ and $\mathrm{Y}_{2} \mathrm{O}_{3}$. Powders calcined at $1200^{\circ} \mathrm{C}$ with further spark plasma sintering allowed for the appearance of orthoferrite peaks in the case of holding times at about 15 and 30 minutes [19].

This paper presents the effect of both processing and precursors in the final magnetic properties of $\mathrm{YFeO}_{3}$ and $\mathrm{Y}_{3} \mathrm{Fe}_{5} \mathrm{O}_{12}$ comparing solid-state reaction, mechano-synthesis plus SPS, and mechano-synthesis plus conventional heating in air and argon.

\section{Experimental}

Samples were prepared following four experimental routes, namely: 1) solid state reaction (SSR), 2) mechano-synthesis followed by conventional heat treatment (MSHT), 3) mechano-synthesis followed by spark plasma sintering (MSSPS), and 4) mechano-synthesis followed by heat treatment in argon (MSHTAr). In all cases, the precursor materials were the same: $\mathrm{FeO}$ and $\mathrm{Y}_{2} \mathrm{O}_{3}$ (Sigma Aldrich, 99.90\% purity).

For the first processing route, SSR 1), stoichiometric amounts of $\mathrm{FeO}$ and $\mathrm{Y}_{2} \mathrm{O}_{3}$ powders were mixed for 15 min and then annealed at $700^{\circ} \mathrm{C}$ or $900^{\circ} \mathrm{C}$ for $3 \mathrm{~h}$ in air to obtain YIG, following the reaction:

$$
3 / 2 \mathrm{Y}_{2} \mathrm{O}_{3}+5 \mathrm{FeO}_{(\text {exc) }}+\mathrm{O}_{2 \text { (from vial) }} \rightarrow \mathrm{Y}_{3} \mathrm{Fe}_{5} \mathrm{O}_{12-\delta}
$$

For the MSHT route 2), stoichiometric amounts of $\mathrm{FeO}$ and $\mathrm{Y}_{2} \mathrm{O}_{3}$ powders as precursors, according to equation (1), were milled in air using a high-energy ball mill (SPEX 8000D) at room temperature for $9 \mathrm{~h}$. Steel balls of $1.27 \mathrm{~cm}$ in diameter and a steel cylindrical vial of $50 \mathrm{~cm}^{3}$ were used, setting up a ball to powder weight ratio of 10:1. This action was then applied alternatively with a 90 min cycle of milling, followed by a 30 min break. Powders were eventually annealed at $700^{\circ} \mathrm{C}$ or $900^{\circ} \mathrm{C}$ for $3 \mathrm{~h}$ in air.

In the case of the MSSPS route 3), the mixture of powders released after mechano-synthesis (90 min of milling) was sintered at $700^{\circ} \mathrm{C}$ and $900^{\circ} \mathrm{C}$, with a heating rate of $100^{\circ} \mathrm{C} / \mathrm{min}$, using the spark plasma sintering (SPS) apparatus Dr. Sinter 1050, applying 5KN of axial load and $6 \times 10^{-2}$ Pa vacuum. The powder to be sintered was placed inside a graphite cylinder matrix of $10 \mathrm{~mm}$ diameter, setting holding times at $700^{\circ} \mathrm{C}$ and $/ \mathrm{or} 900^{\circ} \mathrm{C}$ for 10 min.

Finally, MSHTAr route 4) was performed by heating mechano-synthesized powders in a chamber under Ar 
atmosphere as part of an X-ray diffraction using Panalytical X-Pert Pro equipment from $25^{\circ} \mathrm{C}$ to $950^{\circ} \mathrm{C}$.

Specimens obtained by the four different routes: SSR, MS, MSHT, and MSSPS, were characterized by X-ray diffractometry (XRD) using a Siemens D5000 diffractometer using $\operatorname{CoK} \alpha_{1}(\lambda=1.7889 \AA)$ radiation, while the MSHTAr sample was characterized in a Panalytical X-Pert Pro equipped with a multichannel detector (X'celerator) and by using Co-K $\alpha$ radiation. The specimens' fracture morphology was analyzed using a field emission image FEI Quanta 3D FEG scanning electron microscope operated at $25 \mathrm{kV}$. The magnetic susceptibility and magnetization studies were performed at room temperature using an LDJ 9600 vibrating sample magnetometer with a maximum field of $16 \mathrm{kOe}$.

\section{Results and Discussion}

\subsection{Structural Characterization}

The X-ray diffraction patterns (XRD) of samples were obtained by different methods: i) as ball-milled powder for 9 hours, ii) $\mathrm{Y}_{2} \mathrm{O}_{3}$ and $\mathrm{FeO}$ powder conventionally heat-treated at $700^{\circ} \mathrm{C}$ (SSR), iii) both mechano-synthesized and SPS-treated powder (MSSPS) at $700^{\circ} \mathrm{C}$, iv) both mechano-synthesized and conventionally heat treated (MSHT) specimens at $700^{\circ} \mathrm{C}$, and v) mechano-synthesized and heat treated under argon atmosphere (MSHTAr). These XRD patterns are shown in Figure 1(a).

In the XRD corresponding to $\mathrm{Y}_{2} \mathrm{O}_{3}$ and $\mathrm{FeO}$ powder mixture milled for 9 hours (see Figure 1(i)), the formation of yttrium ferrite with both perovskite and garnet structures ( $\mathrm{YFeO}_{3}$ ICSD \# 43260, $\mathrm{Y}_{5} \mathrm{Fe}_{3} \mathrm{O}_{12}$ ICSD \# 2012, respectively), being predominant in the orthoferrite phase, can be seen. A reflection peak of elemental iron, $\mathrm{Fe}^{0}$ (ICSD \# 64998), is also observed (marked with an arrow in the figure) which can be associated with a reduction of FeO. The evidence of wüstite, FeO (ICSD \# 76639), as traces in this pattern is due to the excess of reactant originally introduced into the vial (regarding stoichiometric orthoferrite) in order to assure garnet structure. Meanwhile, isolated $\mathrm{Y}_{2} \mathrm{O}_{3}$ (ICSD \# 78581) diffraction peaks were not detected in the as-milled condition. In the same Figure 1(a), the $\mathrm{X}$-ray diffraction patterns derived from the powder mixture subjected to the solid state reaction (SSR) route, heat treated at $700^{\circ} \mathrm{C}$, discloses mainly $\mathrm{Fe}_{2} \mathrm{O}_{3}$ and $\mathrm{Y}_{2} \mathrm{O}_{3}$ peaks, which suggest the partial oxidation of $\mathrm{Fe}^{2+}$ to $\mathrm{Fe}^{3+}$ due to the heating, whereas the garnet phase is neither detected nor are or thoferrite peaks observed. In the case of the sample MSSPS treated at $700^{\circ} \mathrm{C}$, the perovskite phase formation takes place, while the garnet phase almost disappears. In this pattern, the $\mathrm{FeO}$ peaks were not detected, but the presence of $\mathrm{Fe}^{0}$ peaks is evident. Although in the XRD patterns corresponding to the MSHT route, the most important phase
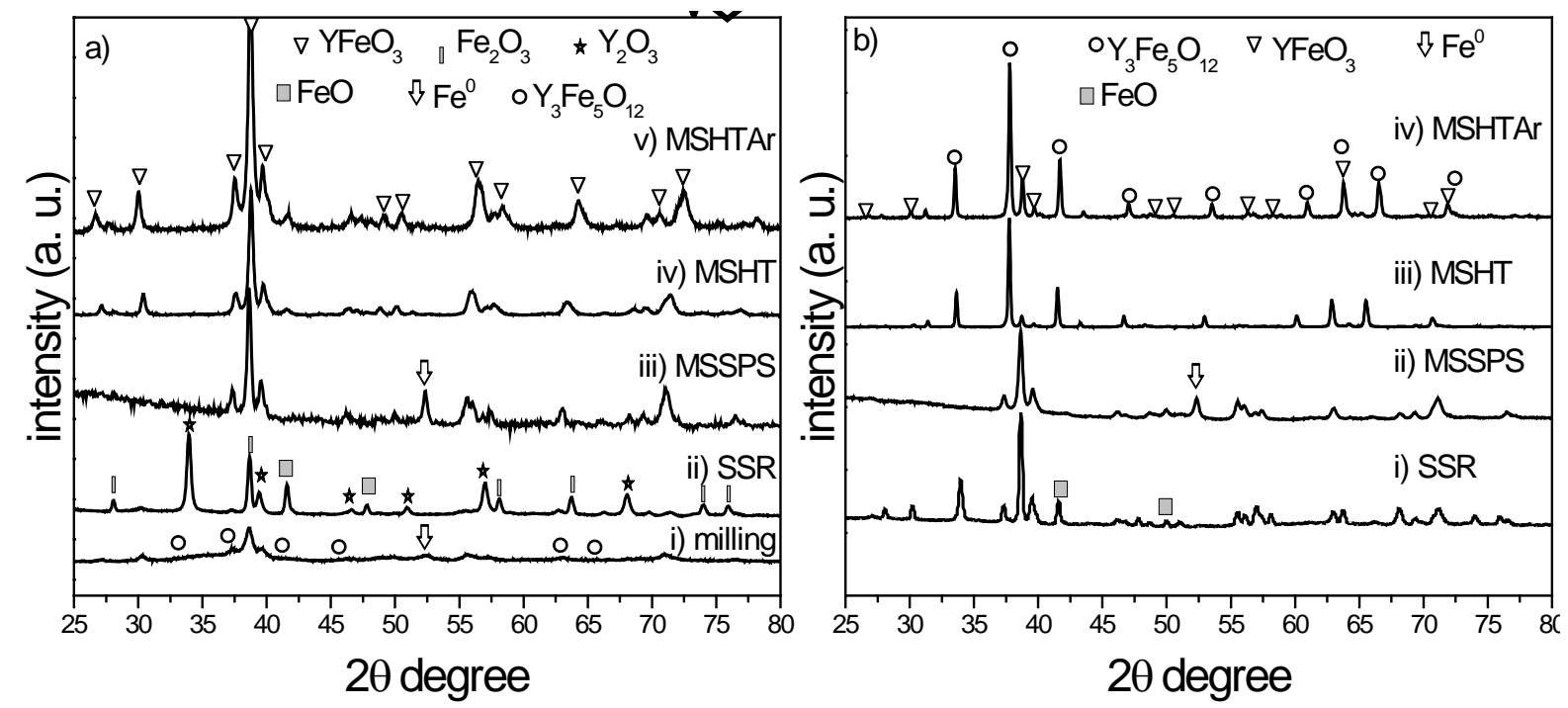

Figure 1. X-ray powder diffraction patterns of: i) $\mathrm{FeO}+\mathrm{Y}_{2} \mathrm{O}_{3}$ as milled; ii) SSR: mixture heat treated at $700^{\circ} \mathrm{C}$; iii) $\mathrm{MSSPS}$ : samples milled and spark plasma sintered at $700^{\circ} \mathrm{C}$; iv) MSHT: samples milled and heat treated at $700^{\circ} \mathrm{C}$; v) MSHTAr: mechano-synthesized powders heat treated under argon atmosphere at $700^{\circ} \mathrm{C}$; vi) SSR: mixture heat treated at $900^{\circ} \mathrm{C}$; vii) MSSPS: samples milled and spark plasma sintered at $900^{\circ} \mathrm{C}$; viii) MSHT: samples milled and heat treated at $900^{\circ} \mathrm{C}$ and ix) MSHTAr: mechano-synthesized powders heat treated under argon atmosphere at $900^{\circ} \mathrm{C}$. 
detected is perovskite. The $\mathrm{Fe}_{2} \mathrm{O}_{3}$ (ICSD \# 43465) phase was found, which indicates an oxidation of $\mathrm{FeO}$, as in SSR route. Also, it is observed for a sample heat treated under argon atmosphere, MSHTAr, that the presence of $\mathrm{Fe}_{2} \mathrm{O}_{3}$ is as that heat treated in air, but there is also a small peak for $\mathrm{Fe}^{0}$.

For all analyzed cases in Figure 1(a) diffraction peaks become narrow and sharp where their intensities increase which implies the grain growth in the microstructure of products, as long as the powder is heated.

The X-ray diffraction patterns of the next samples: vi) conventionally heat-treated $\mathrm{FeO}$ and yttria powder mixture at $900^{\circ} \mathrm{C}$ (SSR), vii) as ball-milled powder for 9 hours and SPS sintered (MSSPS) specimens at $900^{\circ} \mathrm{C}$, and viii) mechano-synthesized and annealed specimens (MSHT), and ix) mechano-synthesized powders heat treated under argon atmosphere at $900^{\circ} \mathrm{C}$ are shown in Figure 1(b). In the case of the solid-state reaction (SSR), the diffraction XRD pattern predominantly shows the presence of the orthoferrite phase, and also hematite and yttrium oxide peaks. In this pattern, diffraction peaks of the garnet phase were not detected. As for the powder mixture treated by MSSPS at $900^{\circ} \mathrm{C}$, the XRD pattern showed a complete disappearance of YIG. Here, the $\mathrm{Y}_{2} \mathrm{O}_{3}$ and $\mathrm{FeO}$ peaks were detected. Despite that diffraction, peaks of $\mathrm{Fe}_{2} \mathrm{O}_{3}$ were observed to disappear at $700^{\circ} \mathrm{C}$ and $900^{\circ} \mathrm{C}$, but the elemental $\mathrm{Fe}^{0}$ peak remains. Both perosvkite and garnet phases were detected for the MSHTsample, the latter acting as the major phase.

By contrast to Figure 1(a), the Bragg peaks reported in Figure 1(b) obtained after any treatment at $900^{\circ} \mathrm{C}$ do present narrower and enlarged peaks (large relative intensities) indicating a growth of grains.

The Rietveld refinement results for the weight percentage of each phase obtained from the XRD patterns analyses are presented in Table 1 . These results confirm the microstructural behavior previously described.

\subsection{Scanning Electron Microscopy}

The scanning electron microscopy (SEM) images of samples sintered at $700^{\circ} \mathrm{C}$ with SPS (MSSPS) are presented in Figure 2. Figure 2(a), annealed (MSHT) and Figure 2(b), solid-state reaction (SSR). Figure 2(c) shows that particles are highly agglomerated and the grain size is not uniform; the grains do not have a regular shape.

Morphology of the fracture for samples sintered at $900^{\circ} \mathrm{C}$ with SPS is shown in Figure 3(a). Here, it is observed that the formation of particles with acute edges is associated with the orthoferrite phase. On the other hand, the mechano-synthesis plus annealed sample of Figure 3(b) clearly shows neck formation. In both series of samples (Figures 2 and 3) grain growth can be seen. In the sample of solid-state reaction Figure 3(c) the formation of liquid-like morphology for joint, but not compacted, particles can be observed.

\subsection{Magnetic Properties}

The magnetic hysteresis loops recorded from specimens processed and sintered by the experimental routes explained in this work are shown in Figure 4. On the left side of Figure 4, samples treated at $700^{\circ} \mathrm{C}$ are shown, whereas their counterparts treated at $900^{\circ} \mathrm{C}$ are shown to the right. There are clear differences in the magnetic response of specimens obtained from the proposed routes. The largest saturation of magnetization induced into the powder mixture, as studied in this work, is attained when following the mechano-synthesis route with subsequent annealing (MSHT) at $900^{\circ} \mathrm{C}$; i.e., specimens could develop values in the order of $25 \mathrm{emu} / \mathrm{g}$, which is close to that of bulk (26 emu/g) [15], even with the presence of $\mathrm{YFeO}_{3}$, which should reduce its magnetization due to its canted antiferromagnetic behavior [29]. This is followed by the mechano-synthesized specimens with subsequent SPS treatment at $700^{\circ} \mathrm{C}$ leading to values around $12.7 \mathrm{emu} / \mathrm{g}$, this magnetic behavior can be influ-

Table 1. Data from Rietveld refinement of XRD patterns in each method.

\begin{tabular}{|c|c|c|c|c|c|c|c|}
\hline Weight \% & Milled 9 h & $\operatorname{MSSPS} 700^{\circ} \mathrm{C}$ & MSHT $700^{\circ} \mathrm{C}$ & $\begin{array}{c}\text { SSR } \\
700^{\circ} \mathrm{C}\end{array}$ & $\begin{array}{c}\text { MSSPS } \\
900^{\circ} \mathrm{C}\end{array}$ & $\begin{array}{l}\text { MSHT } \\
900^{\circ} \mathrm{C}\end{array}$ & $\begin{array}{c}\text { SSR } \\
900^{\circ} \mathrm{C}\end{array}$ \\
\hline $\mathrm{FeO}[23]$ & 1.7 & 0 & 0 & 0 & 2.53 & 0 & 0 \\
\hline $\mathrm{Y}_{2} \mathrm{O}_{3}[24]$ & 0.6 & 0 & 0.18 & 44.87 & 0.67 & 0 & 21.86 \\
\hline $\mathrm{Y}_{3} \mathrm{Fe}_{5} \mathrm{O}_{12}[25]$ & 44.6 & 3.55 & 0.36 & 0 & 0 & 89.73 & 2.12 \\
\hline $\mathrm{YFeO}_{3}[26]$ & 49.9 & 81.19 & 84.47 & 8.12 & 90.85 & 10.27 & 46.08 \\
\hline $\mathrm{Fe}^{0}[27]$ & 3.2 & 15.26 & 0 & 0 & 5.95 & 0 & 0 \\
\hline $\mathrm{Fe}_{2} \mathrm{O}_{3}[28]$ & 0 & 0 & 14.94 & 47.01 & 0 & 0 & 29.94 \\
\hline
\end{tabular}




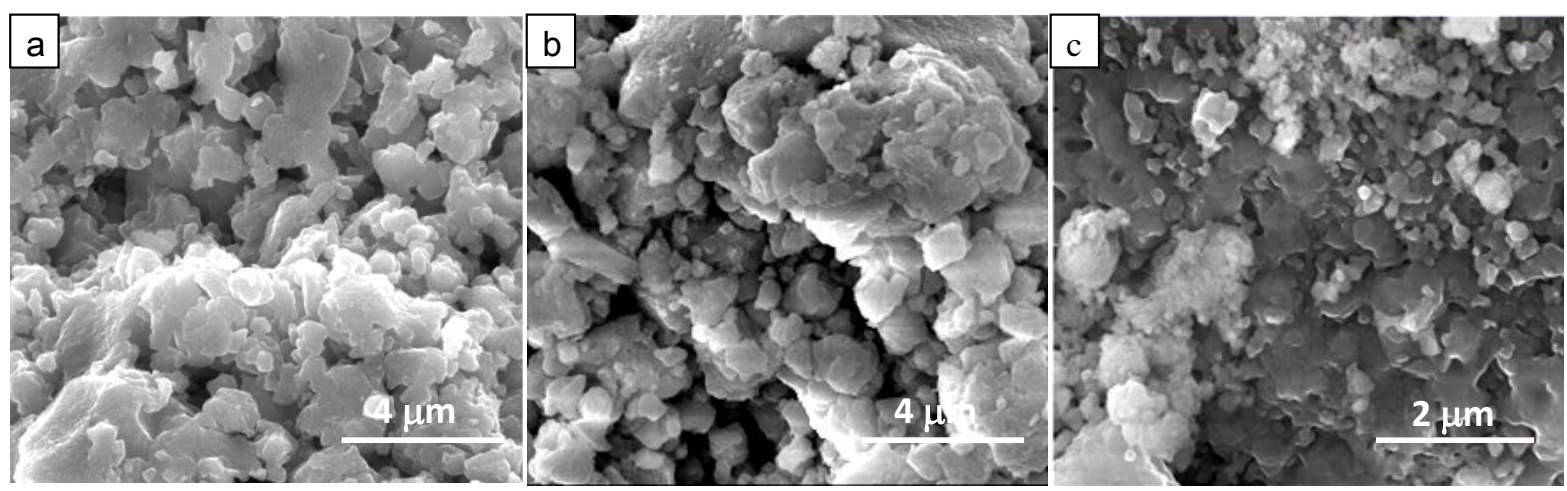

Figure 2. SEM images of the powder mixture after (a) mechano-synthesis plus SPS at $700^{\circ} \mathrm{C}$; (b) mechano-synthesis plus heat treatment at $700^{\circ} \mathrm{C}$ and (c) solid state reaction at $700^{\circ} \mathrm{C}$.
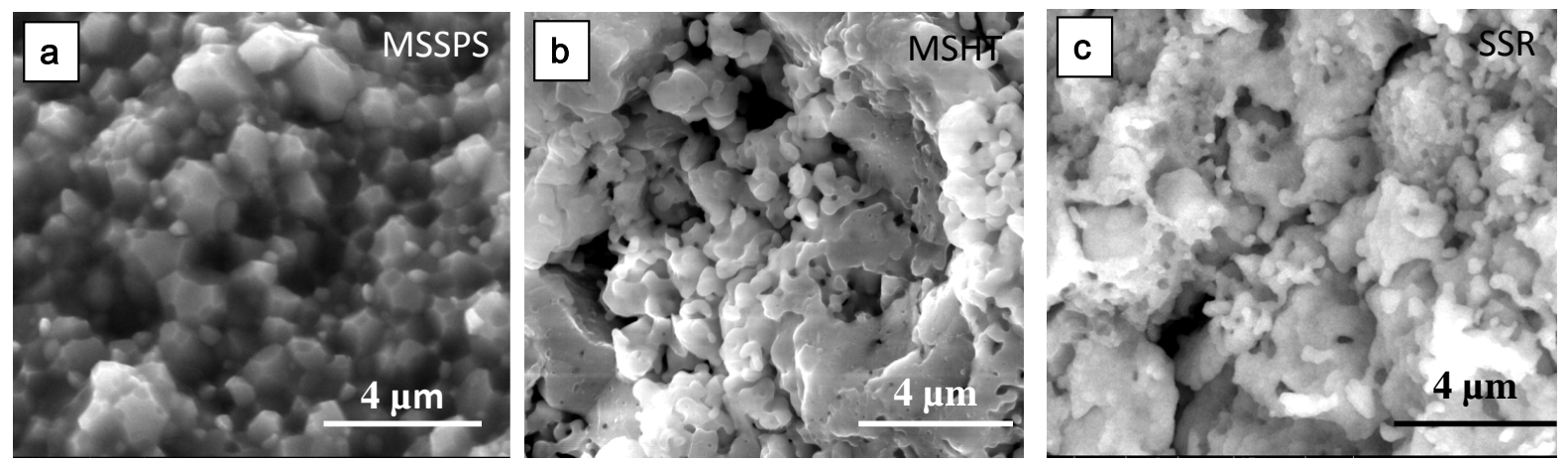

Figure 3. SEM images of the powder mixture after (a) mechano-synthesis plus SPS at $900^{\circ} \mathrm{C}$; (b) mechano-synthesis plus annealing treatment at $900^{\circ} \mathrm{C}$ and (c) solid state reaction at $900^{\circ} \mathrm{C}$.
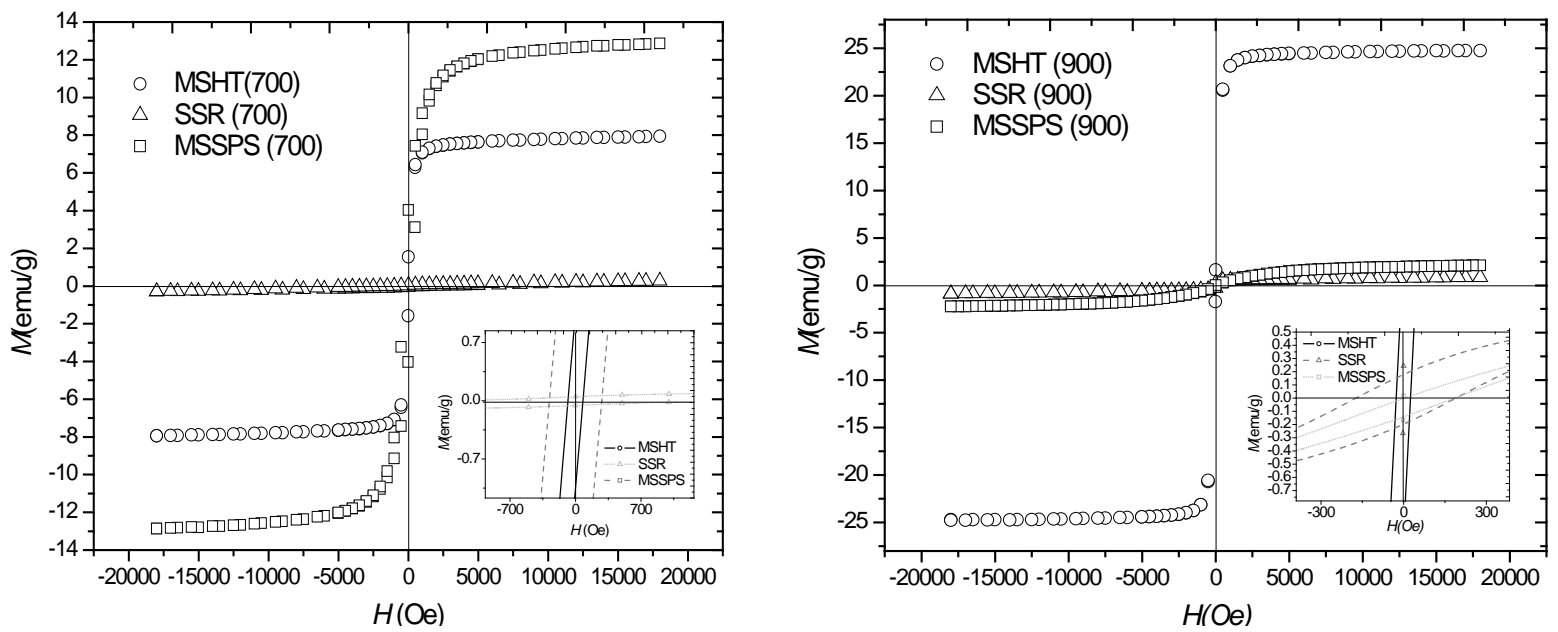

Figure 4. Saturation magnetization (Ms) measured at room temperature for YIG obtain of different methods at $700^{\circ} \mathrm{C}$ and $900^{\circ} \mathrm{C}$.

enced by the presence of $\mathrm{Fe}^{0}$, increasing the saturation magnetization due to its high values ( 221 emu/g) [30]. In the processing case of solid-state reaction, the saturation magnetization of samples treated at $700^{\circ} \mathrm{C}$ and $900^{\circ} \mathrm{C}$ are 0.36 and $0.96 \mathrm{emu} / \mathrm{g}$, respectively. Contrary to what was expected, mixtures obtained do not follow an ideal behavior, i.e. there are interactions between them, which increases its saturation magnetization. On the other hand, as expected, the coercive field seems to be higher for MSSPS samples (see Figure 4) due to lower particle size, only in the case of $700^{\circ} \mathrm{C}$ treatment. In the case of $900^{\circ} \mathrm{C}$, MSSPS samples show a diminution in its 
coercivity associated with grain growth, as is shown in Figure 3(a).

\section{Conclusion}

Four experimental routes have been analyzed in this work as to the preparation of YIG materials, starting from wüstite, $\mathrm{FeO}$, and ittria $\mathrm{Y}_{2} \mathrm{O}_{3}$ powders. When such a ceramic powder mixture is heat-treated, it undergoes different phase precipitations, but without garnet formation, after $900^{\circ} \mathrm{C}$, mainly orthoferrite is obtained. The mechano-synthesis processing route followed by heat treatment (MSHT), as conducted in this work, has been shown to be the most convenient method to increase the $\mathrm{Y}_{3} \mathrm{Fe}_{5} \mathrm{O}_{12} / \mathrm{YFeO}_{3}$ ratio, thus improving the magnetic properties. On the other hand, the precipitation of $\mathrm{YFeO}_{3}$ crystals with larger grain sizes occurring after the SPS treatment at $900^{\circ} \mathrm{C}$ provides clear indications on the garnets' decomposition, due to the severe sintering conditions causing an increment in coercive field and diminution in magnetization saturation. Finally, reducing atmosphere for SPS samples as for heat-treated samples under argon allows the reduction of iron oxide to metallic iron.

\section{Acknowledgements}

Authors would like to thank Centro de Nanociencias, Micro y Nanotecnología del Instituto Politécnico Nacional, in particular to Dr. José Alberto Andraca Adame, Dr. Hugo Martínez Gutiérrez and MSc. Ricardo Escalona for structural, morphological characterization, and SPS sintering, respectively. Thanks are also due to SIP-IPN and CONACYT for financial support under grants SIP MULTI-1540, CB-157925, and CB-130413.

\section{References}

[1] Ali, W.F.F.W., Othman, M., Ain, M.F. and Abdullah, N.S. (2013) Studies on the Formation of Yttrium Iron Garnet (YIG) through Stoichiometry Modification Prepared by Conventional Solid-State Method. Journal of the European Ceramic Society, 33, 1317-1324. http://dx.doi.org/10.1016/j.jeurceramsoc.2012.12.016

[2] Paesano Jr., A., Zanatta, S.C., de Medeiros, S.N., Cótica, L.F. and da Cunha, J.B. (2005) Mechanosynthesis of YIG and GdIG: A Structural and Mössbauer Study. Hyperfine Interactions, 161, 211-220. http://dx.doi.org/10.1007/s10751-005-9193-1

[3] Mergen, A. and Qureshi, A. (2008) Characterization of YIG Nanopowders by Mechanochemical Synthesis. Journal of Alloys and Compounds, 478, 741-744. http://dx.doi.org/10.1016/j.jallcom.2008.11.133

[4] Garskaite, E., Gibson, K., Leleckaite, A., Glaser, J., Niznansky, D., Kareiva, A. and Meyer, H.J. (2006) On the Synthesis and Characterization of Iron-Containing Garnets $\left(\mathrm{Y}_{3} \mathrm{Fe}_{5} \mathrm{O}_{12}\right.$, YIG and $\mathrm{Fe}_{3} \mathrm{Al}_{5} \mathrm{O}_{12}$, IAG). Chemical Physics, 323, 204-210. http://dx.doi.org/10.1016/j.chemphys.2005.08.055

[5] Rashad, M.M., Hessien, M.M., El-Midany, A. and Ibrahim, I.A. (2008) Effect of Synthesis Conditions on the Preparation of YIG Powders via Co-Precipitation Method. Journal of Magnetism and Magnetic Materials, 321, 3752-3757. http://dx.doi.org/10.1016/j.jmmm.2009.07.033

[6] Rossol, F.C. (1970) Domain-Wall Mobility in Yttrium Orthoferrite. Physical Review Letters, 24, 1021-1023. http://dx.doi.org/10.1103/PhysRevLett.24.1021

[7] Didosyan, Y.S. and Hauser, H. (1998) Observation of Bloch Lines in Yttrium Orthoferrite. Physics Letters A, 238, 395397. http://dx.doi.org/10.1016/S0375-9601(97)00757-3

[8] Didosyan, Y.S. and Barash, V.Y. (1995) Faraday Effect in Yttrium Orthoferrite in the Range 1280 - 1600 nm. Journal of Magnetism and Magnetic Materials, 151, 207-210. http://dx.doi.org/10.1016/0304-8853(95)00374-6

[9] Rajendran, M. and Bhattacharya, A.K. (2006) Nanocrystalline Orthoferrite Powders: Synthesis and Magnetic Properties. Journal of the European Ceramic Society, 26, 3675-3679. http://dx.doi.org/10.1016/j.jeurceramsoc.2006.01.008

[10] Didosyan, Y.S., Hauser, H., Wolfmayr, H., Nicolics, J. and Fulmek, P. (2003) Magneto-Optical Rotational Speed Sensor. Sensors and Actuators A, 106, 168-171. http://dx.doi.org/10.1016/S0924-4247(03)00158-4

[11] Fernández-García, L., Suarez, M. and Menéndez, J.L. (2010) Synthesis of Mono and Multidomain YIG Particles by Chemical Coprecipitation or Ceramic Procedure. Journal of Alloys and Compounds, 495, 196-199. http://dx.doi.org/10.1016/j.jallcom.2010.01.119

[12] Zhang, W., Guo, C., Ji, R., Fang, C. and Zeng, Y. (2011) Low-Temperature Synthesis and Microstructure-Property Study of Single-Phase Yttrium Iron Garnet (YIG) Nanocrystals via a Rapid Chemical Coprecipitation. Materials Chemistry and Physics, 125, 646-651. http://dx.doi.org/10.1016/j.matchemphys.2010.10.004

[13] Hosseini Vajargah, S., Madaah Hosseini, H.R. and Nemati, Z.A. (2007) Preparation and Characterization of Yttrium 
Iron Garnet (YIG) Nanocrystalline Powders by Auto-Combustion of Nitrate-Citrate Gel. Journal of Alloys and Compounds, 430, 339-343. http://dx.doi.org/10.1016/j.jallcom.2006.05.023

[14] Vaqueiro, P., López-Quintela, M.A., Rivas, J. and Greneche, J.M. (1997) Annealing Dependence of Magnetic Properties in Nanostructured Particles of Yttrium Iron Garnet Prepared by Citrate Gel Process. Journal of Magnetism and Magnetic Materials, 169, 56-68. http://dx.doi.org/10.1016/S0304-8853(96)00728-7

[15] Guo, X.Z., Ravi, B.G., Devi, P.S., Hanson, J.C., Margolies, J., Gambino, R.J., Parise, J.B. and Sampath, S. (2005) Synthesis of Yttrium Iron Garnet (YIG) by Citrate-Nitrate Gel Combustion and Precursor Plasma Spray Processes. Journal of Magnetism and Magnetic Materials, 295, 145-154. http://dx.doi.org/10.1016/j.jmmm.2005.01.007

[16] Yang, Q., Zhang, H., Liu, Y., Wen, Q. and Jia, L. (2008) The Magnetic and Dielectric Properties of Microwave Sintered Yttrium Iron Garnet (YIG). Materials Letters, 62, 2647-2650. http://dx.doi.org/10.1016/j.matlet.2008.01.040

[17] Fu, Y., Lin, C., Tay, K. and Yao, Y. (2008) Yttrium Iron Garnet Ceramic Prepared from Microwave-Induced Combustion. Journal of Electroceramics, 21, 677-680. http://dx.doi.org/10.1007/s10832-007-9270-8

[18] Suryanarayana, C. (2004) Mechanical Alloying and Milling. Marcel Dekker, New York. http://dx.doi.org/10.1201/9780203020647

[19] Fernández-García, L., Suárez, M. and Menéndez, J.L. (2010) Low Temperature Spark Plasma Sintering of YIG Powders. Journal of Alloys and Compounds, 502, 132-135. http://dx.doi.org/10.1016/j.jallcom.2010.04.117

[20] Jacob, K.T. and Rajitha, G. (2012) Nonstoichiometry, Defects and Thermodynamic Properties of $\mathrm{YFeO}_{3}, \mathrm{YFe}_{2} \mathrm{O}_{4}$ and $\mathrm{Y}_{3} \mathrm{Fe}_{5} \mathrm{O}_{12}$. Solid State Ionics, 224, 32-40. http://dx.doi.org/10.1016/j.ssi.2012.07.003

[21] Veres, A., Noudem, J. G., Fourrez, S. and Bailleul, G. (2006) The Influence of Iron Substitution to Manganese on the Physical Properties of $\mathrm{YMnO}_{3}$. Solid State Sciences, 8, 137-141. http://dx.doi.org/10.1016/j.solidstatesciences.2005.11.002

[22] Cortés-Escobedo, C.A., Bolarín-Miró, A.M., Sánchez de Jesús, F., Valenzuela, R., Juárez Camacho, E.P. and Ammar, S. (2013) $\mathrm{Y}_{3} \mathrm{Fe}_{5} \mathrm{O}_{12}$ Prepared by Mechanosynthesis from Different Iron Sources. Advances in Materials Physics and Chemistry, 3, 41-46. http://dx.doi.org/10.4236/ampc.2013.31A006

[23] Benard, J. (1949) Recherches sur les variations de composition du protoxyde de fer. Bulletin de la Societé Chimique de France, 109-116.

[24] Paton, M.G. and Maslen, E.N. (1965) A Refinement of the Crystal Structure of Yttria. Acta Crystallographica B, 19, 307-310. http://dx.doi.org/10.1107/S0365110X65003365

[25] Bonnet, M., Delapalme, A., Fuess, H. and Thomas, M. (1975) Refinement of the Structure of Yttrium Iron Garnet (YIG). A Case of Severe Extinction and Absorption. Acta Crystallographica Section B, 31, 2233-2240. http://dx.doi.org/10.1107/S0567740875007315

[26] Wu, A., Shen, H., Xu, J., Wang, Z., Jiang, L., Luo, L., Yuan, Sh., Cao, Sh. and Zang, H. (2012) Crystal Growth and Magnetic Property of $\mathrm{YFeO}_{3}$ Crystal. Bulletin of Materials Science, 35, 259-263. http://dx.doi.org/10.1007/s12034-012-0278-6

[27] Owen, E.A and Williams, G.I. (1948 A Low-Temperature X-Ray Camera. Journal of Scientific Instruments, 25, 440444.

[28] Blake, R.L., Hessevick, R.E., Zoltai, T. and Finger, L.W. (1966) Refinement of the Hematite Structure. American Mineralogist, 51, 123-129.

[29] Gil, D.M., Navarro, M.C., Lagarrigue, M.C., Guimpel, J., Carbonio R.E. and Gómez, M.I. (2011) Synthesis and Structural Characterization of Perovskite $\mathrm{YFeO}_{3}$ by Thermal Decoposition of a Cyanocomplexprecursory[Fe(CN6)] $4 \mathrm{H}_{2} \mathrm{O}$. Journal of Thermal Analysis and Calorimetry, 183, 889-896. http://dx.doi.org/10.1007/s10973-010-1176-Z

[30] Danan, H., Herr, A. and Meyer, A.J.P. (1968) New Determinations of the Saturation Magnetization of Nickel and Iron. Journal of Applied Physics, 39, 669-670. http://dx.doi.org/10.1063/1.2163571 